\title{
Knocking on Heaven's Door: User preferences on digital cultural distribution
}

\author{
Joan-Josep Vallbé
}

Department of Political Science, Constitutional Law, and Philosophy of Law, University of

Barcelona, Spain

Balázs Bodó

Institute for Information Law, University of Amsterdam, Amsterdam, Netherlands, bodo@uva.nl

\author{
João P. Quintais \\ University of Amsterdam, Netherlands
}

\section{Christian W. Handke}

Erasmus University Rotterdam, Netherlands

Published on 18 Jun 2019 | DOI: 10.14763/2019.2.1404

\begin{abstract}
This paper explores the social, demographic and attitudinal basis of consumer support of a Copyright Compensation System (CCS), which, for a small monthly fee would legalise currently infringing online social practices such as private copying from illegal sources and online sharing of copyrighted works. We do this by first identifying how different online and offline, legal and illegal, free and paying content acquisition channels are used in the media market using a cluster-based classification of respondents. Second, we assess the effect of cultural consumption on the support for a shift from the status quo towards alternative, CCSbased forms of digital cultural content distribution. Finally, we link these two analyses to identify the factors that drive the dynamics of change in digital cultural consumption habits. Our study shows significant support to a CCS compared to the status quo by both occasional and frequent buyers of cultural goods, despite the widespread adoption of legal free and paying online services by consumers. The nature of these preferences are also explored with the inclusion of consumer preference intensities regarding certain CCS attributes. Our results have relevant policy implications, for they outline CCS as a reform option. In particular, they point evidence-based copyright reform away from its current direction in the EU of stronger enforcement measures, additional exclusive rights, and increased liability and duties of care for online platforms. This work shows that CCS may be an apt policy tool to hinder piracy and potentially increase right holder revenues, while respecting fundamental rights and promoting technological development.
\end{abstract}

Keywords: Online content service providers, Cultural consumption, Copyright compensation system, Digital consumption, User satisfaction 


\section{Article information}

Received: 20 Nov 2018 Reviewed: 17 Feb 2019 Published: 18 Jun 2019

Licence: Creative Commons Attribution 3.0 Germany

Funding: Copyright in an Age of Access: Alternatives to Copyright Enforcement - NWO TOP Grant \#407-11-050

Competing interests: The author has declared that no competing interests exist that have influenced the text.

URL:

http://policyreview.info/articles/analysis/knocking-heavens-door-user-preferences-digital-cultural-dist ribution

Citation: Vallbé, J.-J. \& Bodó, B. \& Quintais, J. P. \& Handke, C. W. (2019). Knocking on Heaven's Door: User preferences on digital cultural distribution. Internet Policy Review, 8(2).

DOI: $10.14763 / 2019.2 .1404$

\section{INTRODUCTION}

Copyright Compensation Systems (CCS) are legal schemes that for a monthly fee would legalise currently infringing online social practices, such as private copying from illegal sources and unauthorised online sharing of copyrighted works. Online enforcement of copyright against p2p networks and their users is ineffective, costly and technically difficult. In the early 200os, when the CCS idea had its first wave of popularity, Eckersley (2004), Fisher III (2004), Grassmuck and Stalder (2003), and Netanel (2003) proposed CCS to replace certain exclusive rights of copyright holders with some form of collective licensing mechanism, which provides blanket authorisation for users to access and use works on the internet in exchange for compensation. A CCS can have many theoretical and practical benefits, such as: monetising previously unmonetised user practices; lowering levels of copyright infringement; reducing costs associated with enforcement; decreasing the transaction costs of obtaining authorisation from rights holders; and increasing legal certainty (Handke, Bodó and Vallbé, 2016). Despite these advantages, rights holders were hoping that private ordering based on strong exclusive rights will ultimately lead to the development of successful legal services, while online piracy will be eliminated through a combination of additional enforcement measures, technical protection measures (TPMs), better monitoring of infringing activities, increased liability on online intermediaries for infringing acts by their users, and increasing penalties for infringement by end-users.

More than 18 years after Napster, the limits of this approach are apparent. While streaming services proliferate, the catalogs of audiovisual services remain limited and fragmented, piracy is still a reality, especially in the audiovisual sector (Poort, Quintais et al., 2018), and looming large over book publishing. Despite legal developments as well as a significant number of high profile and arguably successful court cases against individual users and online platforms, the effectiveness of online copyright enforcement is limited and contested (Poort, Quintais et al., 2018). The development of case law has also revealed that copyright enforcement can conflict with the fundamental rights of individual users (namely as freedom of expression, the protection of privacy and personal data) and online intermediaries' (in particular freedom to conduct 
business) (Quintais, 2017).

Against this backdrop, CCS proposals enjoy a renaissance. It has been demonstrated that a welldesigned CCS alternative has the potential to increase the welfare of consumers, producers, authors and artists by hundreds of millions of Euros a year in the Netherlands alone (Handke, Bodó, and Vallbé, 2016). A recent study demonstrated that certain configurations of CCS are compatible with the European legal framework, and can be arguably implemented without substantial - and thus politically infeasible changes - to the existing European and international copyright regimes (Quintais, 2017). In this paper we explore a third aspect of CCS: its desirability among consumers. Using a survey conducted on a representative sample of Dutch citizens, we first describe the status quo in how entertainment is consumed via online and offline, legal and illegal channels in the Netherlands. We then measure users' willingness to access online cultural works under a CCS regime instead of the alternatives currently available to them. We present a model of consumption behaviour and support for a change to the status quo in copyright compensation. We demonstrate that respondents most eager to switch to flatrate license based alternatives are those with the most extensive experience with available legal digital services. In our view, this finding demonstrates currently unresolved long-term problems with exclusive rights-based digital content markets, while simultaneously pointing to a solution to these problems.

\section{REVIEW OF LITERATURE}

Copyright law is substantially harmonised by international treaties. These set out basic rules and minimum standards regarding substantive law and enforcement measures, while retaining the essential logic of territorial protection. ${ }_{1}$ EU copyright law is harmonised through a series of directives that implement the international rules. The InfoSoc Directive recognises exclusive rights applicable to online use, namely reproduction (applicable e.g. to downloading) and communication to the public (applicable for instance to uploading and hyperlinking), as well as a number of exceptions or limitations to the same. As a rule, rights are interpreted broadly and exceptions narrowly (e.g., private copying does not cover downloading from unauthorised sources). The Enforcement Directive contains provisions on civil enforcement measures for all intellectual property rights, including injunctive relief and damages. Finally, the E-Commerce Directive sets forth liability exemptions or "safe-harbors" for certain intermediaries and prohibits the imposition of general monitoring obligations. 2

The concept of digital "piracy" refers to online acts that under national law trigger the application of exclusive rights but are not authorised by the copyright holder, or, do not benefit from exceptions. These copyright infringing acts do not generate compensation or remuneration for copyright holders.

CCS proposals emerged in response to widespread digital piracy and the lack of legal offers of digital content services in the first half of the 2000s. Various authors (Eckersley, 2004; Fisher III, 2004; Grassmuck and Stalder, 2003; Netanel, 2003) proposed to solve this problem through a legal mechanism consisting of a blanket license for otherwise unauthorised online use of copyright-protected content by end-users (a CCS). Such a system could address problems with piracy, while producing a number of desirable effects. First, it would increase legal certainty and reduce the transaction costs of acquiring the appropriate licenses to cover all the territorial rights fragments required to enable mass cross-border online use of protected content. Second, CCS would remove arbitrary barriers to licensing, leading to increased 
competition among digital service providers. In turn, this could lead to better online content services and wider access to a more diverse range of protected content. Third, CCS would reduce the direct and indirect costs of enforcement. This would include the costs of private parties with litigation, monitoring of infringing acts, and other private enforcement practices. It would likewise include public costs of enforcement, including those arising from conflicts with fundamental rights of users and online intermediaries.

From a different perspective, CCS proposals impose a cost on copyright holders. These proposals restrict the exercise or scope of exclusive rights, such as the rights of reproduction and communication to the public that apply to online acts by internet users. The restrictions are accompanied by rules ensuring a corresponding remuneration or compensation for copyright holders (or solely creators) of works included in the system. The result is that a previously unauthorised use becomes "permitted-but-paid" (Ginsburg, 2015). The legal schemes underlying such proposals vary, and range from different models of collective rights management (voluntary, extended or mandatory), statutory licenses (accompanied by compensated exceptions to the affected rights), and even state-funded systems (Quintais, 2017).

A contrasting policy option to a CCS would be to strengthen the exclusive rights and enforcement measures available to copyright holders. In theory, this would place them in a better position to fight infringement and transact with online intermediaries and service providers. Indeed, this has been the recent trend in copyright law and policy. In general, copyright holders have been successful in asserting new rights in the digital domain (Kunz, 2016), and defining, via court cases, the contours of secondary liability of online intermediaries, including internet service providers for the copyright infringing activities of their users (ElkinKoren, 2014; Angelopoulos, 2016). A recent manifestation of this trend at the EU level is found in the recently approved Directive for Copyright in the Digital Single Market. Article 17 thereof (previously numbered as Article 13 in the legislative process) changes the regulation of "online content-sharing service providers", defined as online intermediaries hosting large amount of copyright-protected content uploaded by its users, for profit-making purposes (e.g., YouTube, Facebook and Vimeo, as well as a broad range of much smaller user-generated content platforms). In simple terms, it removes the safe-harbour protection for these platforms and makes them liable for acts of communication to the public. As a result, they must either obtain licenses from rights holders or, if they are not able to do so, comply with a number of obligations, including the imposition of filtering measures. 3 In addition, as copyright in the digital domain became better defined, rights holders, especially in the music industry overcame their initial reluctance, and started to license digital music services selling (iTunes in 2001), and providing free (YouTube in 2005) or flat rate streaming (Spotify in 2006, Youtube Premium in 2015) access to musical works.

However, despite all these developments, many of the fundamental problems that emerged almost two decades ago persist. While a large number of music streaming services offer unlimited access to an almost limitless musical catalogue, 4 audiovisual digital streaming platforms have a harder time to license content in a much more fragmented audiovisual content licensing landscape (Braxton, 2013). In addition, many traditional audiovisual content producers, who have their own competing distribution platforms (such as broadcast or cable TV networks) refuse licensing to independent intermediaries, such as Amazon or Netflix, forcing these newcomers to develop independent content (Macdonald, 2014). Likewise, a combination of transaction costs and anti-competitive behaviour so far prevented a Spotify-like universal access to literary works, and other printed material. 
Evidence suggests that streaming services contributed to a gradual fall in the levels of copyright infringement (Bahanovich and Collopy,2009; Poort and Weda, 2015; Poort, Quintais et al., 2018) in certain but not all markets. Consequently, copyright infringement of audiovisual works, in forms such as illegal streaming services is still functioning (British Music Rights, 2008; Swedish Performing Rights Society, 2009; Poort and Leenheer, 2012; Kantar Media, 2012; Bounies et al., 2012; Watson et al., 2014; Poort et al., 2018). The public and private costs associated with copyright enforcement are significant (Bomsel and Ranaivoson, 2009). Private costs burden rights holders as well as online intermediaries, which need to comply with increasing duties of care required to benefit from safe-harbours (e.g., those related with noticeand-takedown measures), as well as with obligations related with enforcement measures for infringing third-party activities of users of their services (e.g., website blocking, notice-andtakedown or staydown, and content filtering). The public has to face costs associated with the impact of copyright enforcement on end-users privacy and freedom of expression and information (Bar-Ziv and Elkin-Koren, 2017; Reda, 2017; Urban et al., 2005; Urban et al., 2018), cultural diversity (Jacques, Garstka et al., 2018), as well as online platforms' freedom to conduct business.

In summary, digital cultural distribution still suffers from significant shortcomings. Individual users and consumers, who wish to access music, films and books in a digital format, for a reasonable price, in a legal convenient manner are often unable to do so. Copyright holders often fail to receive adequate compensation (Cooper and Griffin, 2012; Warner Music Group, 2010; Kampmann, 2010; Swedish Performing Rights Society, 2009; Kantar Media, 2012). Therefore, a CCS-based solution needs to be assessed not just for its legal feasibility(Quintais, 2017) or economic impact (Handke, Bodó, and Vallbé, 2016), but also for its level of support among users, namely those consumers affected by the potential introduction of a flat-rate content access model.

Today, digital cultural consumption follows a hybrid pattern: the use of various legal, free and paid consumption channels is occasionally complemented by the use of piratical channels (Kantar Media, 2012; Poort and Leenheer, 2012; Poort et al., 2018). ${ }_{5}$ CCS can complement or even fully substitute existing consumption practices - piratical and legal - provided users consider it an attractive alternative to the status quo.

Previous studies that measured support for some version of a CCS showed substantial demand for such a service (Grassmuck, 2009). Various studies conducted before the appearance of Spotify demonstrated substantial (75\%-90\%) support for a monthly levy based license, with a willingness to pay in the price range of $€_{5}$ to $€ 15$, that streaming services currently occupy (Bahanovich and Collopy, 2009; Entertainment Media Research, 2011; Renkema and Karaganis, 2012; SPEDIDAM, 2005; Swedish Performing Rights Society, 2009). Most of these studies agree that even "pirates" who access content in a copyright infringing manner support the CCS idea.

Our study adds to this literature in a number of ways. First, using the conjoint survey method, we prove that it is possible to elicit meaningful policy choices from averagely informed citizens in a highly complex regulatory domain. Second, this method allows us to test more than just the willingness to pay for a predefined license. Instead, we are able to rank a large number of alternatives and to measure the part-worth of legally and economically relevant individual license components. Third, we look at consumer support for a levy-based CCS alternative in the context of existing cultural consumption practices. In particular, this paper addresses the following questions: 
1. Given the variety of legal and illegal, free and paying, online and offline channels, how do Dutch individuals consume music, audiovisual works and books?

2. How can we explain and contextualise copyright infringement in light of hybrid consumption patterns?

3. How large is the support for a license-based access alternative? What are the determinants of such support?

4. How would the introduction of such an alternative upset the currently observable media consumption patterns?

\section{THEORETICAL MODEL AND HYPOTHESES}

Our theoretical model highlights the factors that explain support for a change in the status quo in copyright management from the users' perspective. We model individual support for a change to the status quo largely as a function of the frequency of use and the volume of content acquired through different consumption channels across different content types (consumption habits).

Cultural habits depend strongly on individual structural characteristics that include age, level of education, income and place of residence (Bourdieu, 1984; Poort and Weda, 2015). These have also been found to determine the unequal distribution of skills and resources that explain the so-called "digital divide". Given the relevance of the consumption channel in our definition of cultural habits, in our first hypothesis $\left(H_{1}\right)$ we expect to find that older people present more traditional patterns of consumption, while younger and well-educated respondents embrace mostly digital-based consumption habits.

The model also contemplates that consumption habits are affected by individual preferences on cultural consumption. Music lovers interested in the continuous discovery of new recordings or in the ability to access an artist's complete catalogue may be strongly attracted to the search capabilities offered by online music platforms and archives. In contrast, traditional bookworms may find an intrinsic value in the process of buying, reading or collecting physical books. In accordance, our second hypothesis $\left(\mathrm{H}_{2}\right)$ states that, keeping sociodemographic factors constant, those having stronger preferences for elements associated with digital consumption - such as a wider user rights or artists' catalogues - will be more likely to adopt digitally-based cultural consumption, whether legal or illegal.

Finally, our model predicts support for the establishment of a CCS (i.e., a change in the status quo) as a function of cultural consumption habits and preferences. We start from the naive assumption that the rapid development and adoption of a variety of legal access channels would be associated with a support for the status quo, since users may be satisfied with the new services. Accordingly, our third hypothesis $\left(\mathrm{H}_{3}\right)$ is that traditional and non-traditional consumers are unlikely to choose an alternative to the status quo, albeit for different reasons. In particular, we expect low support for a CCS among those who do not use digital access channels in the first place. Given the low level of enforcement in the Netherlands, those who acquire music, films or books through illegal sources may also find the fee-based CCS option unappealing. We also expect those consumers who already use legal digital platforms have few incentives to switch to a flat fee based alternative if they find existing legal alternatives satisfactory. 


\section{METHODS AND DATA}

This study is based on the results of two surveys we conducted on the LISS panel 6, a representative sample of Dutch citizens aged 16+ (including those without internet connection) in November 2012. The initial sample included all 6,216 active panel members aged 16 years or older, of which 4,968 (79.9\%) completed the choice experiment and responded to all other survey questions (Handke, Bodó, and Vallbé, 2016). There is some evidence of potential nonresponse bias, given that non-respondents are younger, still studying, or self-employed, still living with their parents or with their unwedded partners in larger cities. This yields an underrepresentation of 'digital natives' in our sample, and an overrepresentation of older people and respondents living in rural environments. Since the latter characteristics are typically associated with a low probability of accepting (or even being familiar with) any CCS option, this is probably a source of underestimation of the share of digital users in our data.

In the first survey we asked respondents to report their media consumption habits. We asked questions on the amount and frequency of purchases on various offline and online, legal free (ad-supported), subscription based and pay-per-use (PPU), as well as illegal content distribution channels for music, audiovisual content and books. In the second survey we conducted a conjoint experiment in which the payment mechanism of the CCS was defined as a surcharge to the internet subscription fee, and respondents were informed that the functioning of the CCS (including the distribution of revenues) would occur under statutory regulation.

In the conjoint survey, CCS alternatives were defined by the combination of the following attributes.

- Allowed uses covers the rights that a CCS would provide participating users regarding the use of content, with three levels of use: (1) downloading only; (2) downloading and sharing, and (3) downloading, sharing and modifying (including the right to create and disseminate derivative works).

- Subject matter corresponds to the type of content that a CCS would make available, with three possible configurations: (1) recorded music only; (2) recorded music and audiovisual works, and (3) recorded music, audiovisual works and books.

- Catalogue completeness. It concerns the scope of a CCS license regarding artists' works. Its levels are: (1) complete catalogue; (2) temporal restrictions; and (3) partial catalogue, i.e. catalogues with permanent restrictions.

- Monitoring. The monitoring attribute has two levels: (1) any CCS participation is associated with anonymous monitoring; (2) there is a statutory guarantee of no monitoring.

- Distribution of revenues. This attribute has two levels: (1) the CCS would provide original creators with at least $50 \%$ of the CCS revenues; (2) creators (authors and performers) would be free to negotiate their revenue share with investors or intermediaries.

- Price. The conjoint experiment covered six five Euro price points from $€_{5}$ to $€_{30}$.

All the possible combinations of attribute levels would yield 648 different CCS alternatives, which cannot be tested with a reasonably sized sample. Through efficient factorial design we created 54 choice sets, 27 for each payment treatment option. Respondents were randomly presented with 12 choice-sets consisting of two utility balanced CCS options and a 'choose none' option. For further information on the method, especially about the considerations around measuring price with contingent valuation methods, see (Handke, Bodó, and Vallbé, 2016).

\subsection{CLASSIFYING CONSUMPTION HABITS}

Our data set contains 28 questions related to the respondents' cultural consumption habits. 
Consumption is conceptualised in three dimensions: time since the last purchase or acquisition, the amount consumed, and the channel of consumption. 7

In order to obtain a classification of all respondents according to their consumption, we apply a clustering algorithm to all 28 variables concerning cultural consumption habits. A clustering algorithm divides a collection of individuals into a set of similar groups, or clusters, so that individuals within a cluster are as similar as possible, and individuals in one cluster are as dissimilar as possible from individuals in other clusters (Manning et al., 2008). Similarity is measured through the standard Euclidean distance metric. 8

\subsection{MODEL OF CULTURAL CONSUMPTION HABITS}

Once we get a classification of all respondents into clusters or typologies of consumers, we will test our first two hypotheses to explain cultural consumption through two types of explanatory variables: sociodemographic and attitudinal. The respondents' main sociodemographic characteristics include age, sex, income and level of education, and of contextual factors such as household size, and the level of urbanisation of the respondents' city. On the other hand, we want to test whether respondents' preferences regarding certain aspects of cultural digital consumption affect their cultural consumption behaviour. Our data set contains questions regarding to what extent respondents have weak or strong preferences on the attributes of a CCS.

Given that our response variable is a unordered polytomous measure (the different clusters representing types of consumer), we fit a multinomial logistic regression model on the type of consumer.

\subsection{MODEL OF WILLINGNESS TO CHANGE}

In our third hypothesis we want to test to what extent consumption behaviour can explain respondents' readiness to change the status quo in copyright policy. We measure readiness to change through a continuous variable that measures the respondents' distance towards the status quo, which we calculate from the discrete choice results. In the experiment each respondent was faced with 12 choice sets, each of which contain three alternatives: two CCS alternatives containing a different combination of attributes, and a no-choice (or "none") option. To operationalise distance, we take the number of times a respondent chose the "none" option as an indicator of her proximity to the status quo. Figure 1 shows the frequency distribution of respondents by the number of times the "none" option was chosen. 32 percent of respondents (referred to here as "nay-sayers") opted for the no-choice option in all the choice sets they were faced with (12), and therefore are closest to the status quo. In contrast, 29 percent always preferred some alternative to the status quo (i.e., never chose the "none" option), thus being farthest from the status quo. In order to operationalise proximity as distance, we just subtracted the times each respondent chose the "none" option to 12. 


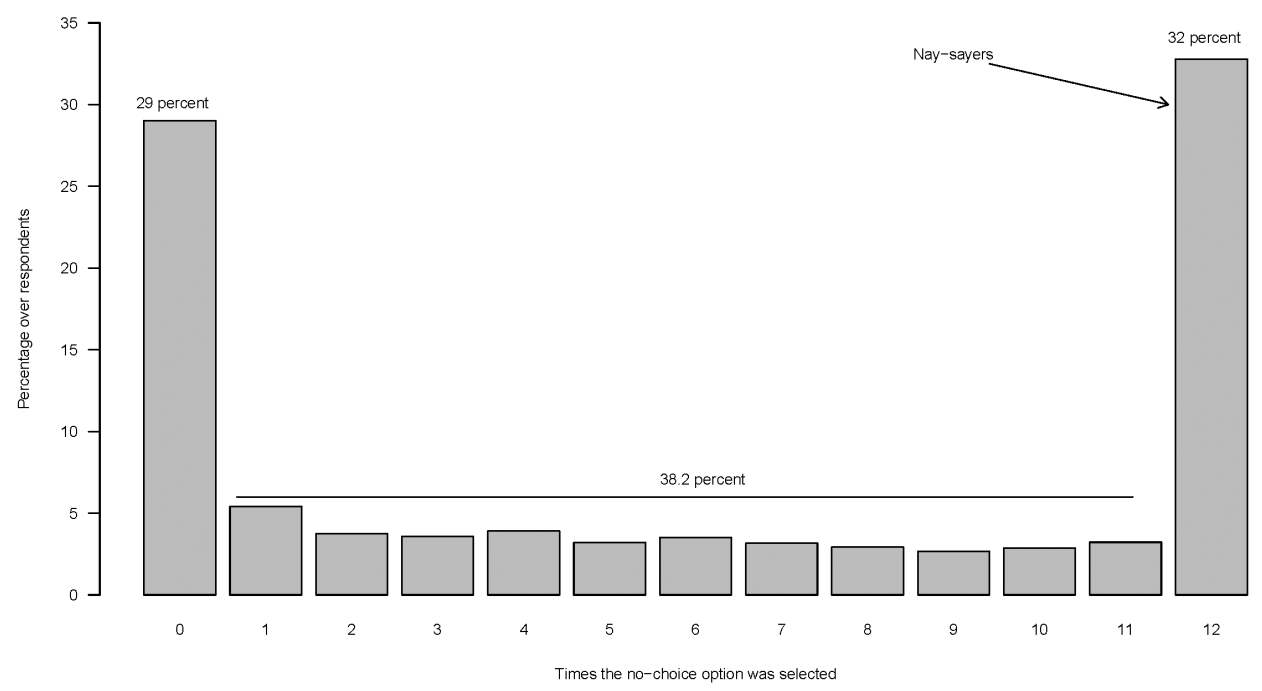

Figure 1: Distribution of times respondents chose the no-choice option in the discrete choice experiment on copyright compensation systems.

To explain the respondents' readiness to change from their consumption behaviour, we follow two different strategies. First, we fit a linear regression model (OLS) of the distance towards the status quo on the type of consumption controlling for the main sociodemographic factors. To ease interpretation, the distance measure has been normalised to have values between 0 and 10. We model the distance to the status quo as a function of the type of consumer, plus a number of sociodemographic and attitudinal control variables. 9

\section{MAIN EMPIRICAL RESULTS}

\subsection{CLUSTERS OF CONSUMERS}

Table 1shows average scores of each variable of media consumption for each of the five clusters provided by the algorithm. Since consumption data are three-dimensional (time, amount and channel) the interpretation of the results must take all three elements into account. Let's focus on the fourth numeric column of Table 1. Individuals in this cluster are characterised by very high scores in all time-related variables, which indicates that their last consumption (whatever the amount and the channel) took place a long time ago (more than one year). Moreover, individuals in this cluster present the lowest average scores in all the amount-related measures, indicating that they acquired only a very small amount of cultural goods. In essence, these are individuals that almost never consume and do so in small amounts. We have therefore labeled them as non-consumers. They represent 28 percent of the population.

The first-column cluster represents mainly the occasional cultural consumers (29 percent of the population). They are low-intensity consumers in both time and amount, but with a stronger preference for free music (e.g., radio or free Spotify accounts) and certain reliance on physical purchases. In contrast, bookworms (20 percent) are defined by their low interest in music and audio-visual content, and by a rather high intensity of book consumption in both time and amount, which is almost exclusively focused on books in physical format. The third column in Table 1 represents the smallest group of consumers (6.4 percent), which we call digital cultural omnivores. They consume through paid subscriptions (mostly music and films), although they 
also rely on physical formats for all types of goods. 10 Finally, the second-column cluster represents what we call pirates. These present similar cultural habits to digital consumers (they are also cultural omnivores), but their main difference with digital consumers is to be found in their high levels of consumption through illegal sources (see second column of Table 1). They represent 16 percent of the respondents.

Table 1: Cluster means of the Hierarchical Clustering results (Ward method).

\begin{tabular}{|c|c|c|c|c|c|}
\hline \multicolumn{2}{|c|}{ Occasional } & Pirate & Digital & Non-consumer & Bookworm \\
\hline \multicolumn{2}{|l|}{$\begin{array}{l}\text { Music } \\
\text { Time }\end{array}$} & & & & \\
\hline Physical buy & 5.97 & 6.00 & 5.72 & 6.84 & 6.05 \\
\hline Paid download & 6.62 & 6.16 & $5 \cdot 57$ & 7.09 & 6.80 \\
\hline Paid subscription & 6.56 & 6.24 & 1.92 & 7.13 & 6.88 \\
\hline Free & 2.68 & 3.15 & 2.53 & 7.09 & 6.69 \\
\hline Pirate & 6.50 & 4.00 & 5.69 & 7.12 & 6.96 \\
\hline \multicolumn{6}{|l|}{ Amount } \\
\hline Physical buy & 0.90 & 0.88 & 1.10 & 0.39 & 0.83 \\
\hline Paid download & 0.23 & 0.46 & 0.91 & 0.03 & 0.16 \\
\hline Free & 1.67 & 1.76 & 2.67 & 0.04 & 0.20 \\
\hline Pirate & 0.36 & 2.08 & 1.04 & 0.02 & 0.11 \\
\hline Paid subscription & 0.23 & 0.38 & $15 \cdot 41$ & 0.01 & 0.09 \\
\hline \multicolumn{6}{|l|}{$\begin{array}{l}\text { Film/TV } \\
\text { Time }\end{array}$} \\
\hline Physical buy & 5.80 & 5.25 & 5.50 & 6.85 & 5.89 \\
\hline Paid download & 6.95 & $5 \cdot 79$ & $5 \cdot 93$ & 7.07 & 6.95 \\
\hline Paid rental & 6.95 & $5 \cdot 37$ & 5.68 & 7.09 & 7.00 \\
\hline VOD & $5 \cdot 49$ & 5.28 & 5.16 & 7.04 & 6.87 \\
\hline Pirate & 6.97 & 3.13 & $5 \cdot 44$ & 7.08 & 7.00 \\
\hline \multicolumn{6}{|l|}{ Amount } \\
\hline Physical buy & 0.93 & 1.09 & 1.11 & 0.25 & 0.77 \\
\hline Paid download & 0.08 & 0.49 & 0.67 & 0.03 & 0.05 \\
\hline Paid rental & 0.07 & 0.75 & 0.89 & 0.02 & 0.03 \\
\hline VOD & 0.81 & 0.83 & 1.15 & 0.05 & 0.13 \\
\hline Pirate & 0.10 & 2.60 & 1.19 & 0.01 & 0.05 \\
\hline $\begin{array}{l}\text { Books } \\
\text { Time }\end{array}$ & & & & & \\
\hline
\end{tabular}




\begin{tabular}{|l|l|l|l|l|l|}
\hline \multicolumn{2}{|c|}{ Occasional } & Pirate & Digital & Non-consumer & Bookworm \\
\hline Physical buy & 4.54 & 4.22 & 4.17 & 6.62 & 2.99 \\
\hline Paid download & 6.82 & 6.07 & 6.38 & 7.08 & 6.59 \\
\hline Paid rental & 7.02 & 6.42 & 6.81 & 7.09 & 7.01 \\
\hline Pirate & 6.94 & 5.64 & 6.37 & 7.08 & 6.68 \\
\hline Amount & & & & & \\
\hline Physical buy & 1.65 & 1.63 & 1.82 & 0.53 & 2.32 \\
\hline Paid download & 0.16 & 0.39 & 0.53 & 0.01 & 0.27 \\
\hline Paid rental & 0.03 & 0.18 & 0.25 & 0.00 & 0.01 \\
\hline Pirate & 0.12 & 0.88 & 0.66 & 0.01 & 0.40 \\
\hline
\end{tabular}

\subsection{DETERMINANTS OF CULTURAL CONSUMPTION}

Once each respondent is classified as a particular type of consumer (i.e., in a cluster), we can explore what factors correlate with the cultural consumption habits of each group. The response variable in this model is the type of consumer. Detailed tabular results can be checked in Table 3 , in the Appendix. Model A includes only controls for sociodemographic factors. The effect of the intensity of preferences can be observed in Model B. To improve readability of results, Table 2 presents the average values of each independent variable for each type of consumer.

The regression results show that age and education are important predictors of cultural consumption habits. Moreover, digital consumers and pirates present similar socio demographic profiles. As expected, older respondents present lower chances of being pirates or digital consumers, and higher chances of being bookworms, than non-consumers. The first row of Table 2 shows that non-consumers and bookworms present much older average age profiles, while pirates and digital consumers are notably younger.

Table 2: Average and most common values of each independent variable for each type of consumer. For education and type of residence, values are column percentages.

\begin{tabular}{|l|l|l|l|l|l|}
\hline & Non-consumer & Pirate & Occasional & Digital & Bookworm \\
\hline Age & 60.99 & 37.24 & 47.31 & 40.56 & 59.00 \\
\hline $\begin{array}{l}\text { Median income } \\
(€ 1 \text { 1000 })\end{array}$ & 1.25 & 1.25 & 1.38 & 1.55 & 1.55 \\
\hline $\begin{array}{l}\text { Average } \\
\text { (ncome } \\
(€ 1 \text { 10oo })\end{array}$ & 1.36 & 1.26 & 1.39 & 1.56 & 1.61 \\
\hline $\begin{array}{l}\text { Household size } \\
\text { Education }(\%)^{a}\end{array}$ & 2.28 & 2.85 & 2.72 & 3.05 & 2.34 \\
\hline Primary $^{a}$ & 13.64 & 9.44 & 7.26 & 10.85 & 4.48 \\
\hline
\end{tabular}




\begin{tabular}{|c|c|c|c|c|c|}
\hline & Non-consumer & Pirate & Occasional & Digital & Bookworm \\
\hline vmbo & 39.45 & 16.09 & 21.64 & 12.88 & 23.02 \\
\hline mbo & 22.19 & 22.61 & 25.24 & 23.73 & 21.04 \\
\hline havo/vwo & 6.70 & 17.02 & 11.23 & 14.58 & 10.83 \\
\hline hbo & 14.56 & 22.74 & 25.53 & 24.07 & 30.42 \\
\hline wo & 3.47 & 12.10 & 9.10 & 13.90 & 10.21 \\
\hline \multicolumn{6}{|l|}{ Residence (\%) } \\
\hline $\begin{array}{l}\text { Highly } \\
\text { urbanised }\end{array}$ & 11.09 & 14.67 & 13.25 & 17.18 & 12.05 \\
\hline Urbanised & 24.10 & 28.94 & 25.97 & 29.55 & 26.00 \\
\hline $\begin{array}{l}\text { Moderately } \\
\text { urbanised }\end{array}$ & 23.94 & 24.05 & 24.14 & 22.34 & 23.38 \\
\hline $\begin{array}{l}\text { Little } \\
\text { urbanised }\end{array}$ & 23.40 & 19.57 & 20.53 & 17.53 & 23.27 \\
\hline $\begin{array}{l}\text { Not urbanised } \\
\text { Preference } \\
\text { intensity }^{b}\end{array}$ & 17.47 & 12.77 & 16.11 & 13.40 & 15.30 \\
\hline User rights & 2.22 & 4.40 & $3 \cdot 52$ & 4.48 & 2.83 \\
\hline $\begin{array}{l}\text { Types of } \\
\text { content }\end{array}$ & 2.23 & 4.87 & 3.99 & 4.92 & 3.01 \\
\hline $\begin{array}{l}\text { Catalog } \\
\text { completeness }\end{array}$ & 2.21 & 4.51 & 3.73 & 4.51 & 2.98 \\
\hline $\begin{array}{l}\text { Artists } \\
\text { payment }\end{array}$ & 2.32 & 4.07 & 3.59 & 4.20 & 3.15 \\
\hline \multicolumn{6}{|c|}{$\begin{array}{l}{ }^{a} \text { Dutch educational levels refer to: VMBO (pre-vocational), MBO (vocational), HAVO/VWO } \\
\text { (secondary), WO (higher education) } \\
{ }^{b} \text { Value range from } 1 \text { to } 7 \text {. }\end{array}$} \\
\hline
\end{tabular}

Also, the chances of being any type of cultural consumer - compared to a non-consumer increase with education. For instance, at the same age and similar levels of income, the odds of being a pirate instead of a non-consumer will increase by 2.3 if moving from primary to secondary education (havo/vwo), and they will be 4.5 times higher if moving from primary to university education. The same pattern holds for the remaining types of cultural consumers, although the impact of education is naturally highest among bookworms.

The significant combined effect of age and education on consumption habits can be better observed in Figure 2. The plot represents the probability of being each type of consumer at all combinations of education and age. ${ }_{11}$ For instance, let's focus on pirates. At all levels of education the relative probability of being a pirate remains stable within age categories but changes dramatically across them. If, for example, we now focus on the younger group of respondents, the probability of being a pirate remains high regardless of their level of education; conversely, that probability remains very low among older respondents at all educational levels. In contrast, the probability of being a book lover or a non-consumer changes across both age 
groups and education levels.

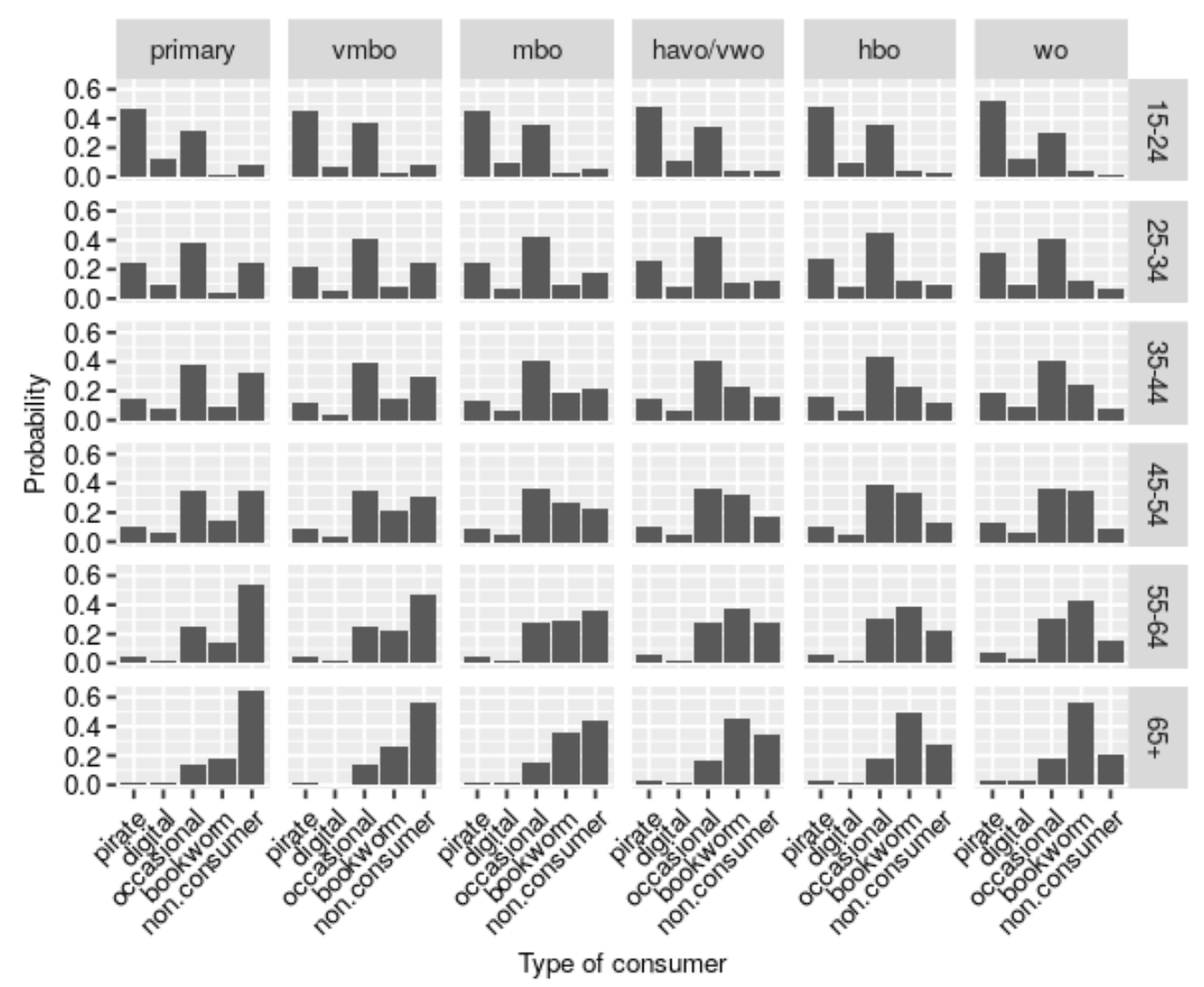

Figure 2: Probability of being each type of consumer by level of education and age.

Furthermore, the inclusion of controls for attitudinal questions does not change the coefficients of the structural factors while significantly improving the model fit, which serves as a robustness check for the analysis. Respondents with stronger preferences for the rights provided by a CCS are likelier to be pirates or digital consumers rather than non-consumers.

\subsection{USERS' READINESS TO CHANGE}

To test our third hypothesis we turn to the regression model of readiness to change in relation to the type of consumer. The dependent variable is the distance to the status quo. 12 Although coefficients in the OLS and Poisson models are in different scale, estimates indicate that both modeling strategies arrive at the same results, serving as a robustness check for the analysis.

In a first specification we regressed distance on the type of consumer without any other intervening factor. As expected, all types of consumers are on average farther away from the status quo compared to non-consumers. However, in sharp contrast with our naive hypothesis, digital consumers and pirates lead the way for change, followed by occasional consumers. In particular, without any control variables, digital buyers are on average 4.7 points (in the $0-10$ scale) farther from the status quo than non-consumers, while the distance differential is 3.8 for pirates and 2.5 for occasional consumers. Figure 3 plots the predicted distance to the status quo of the five types of consumer (from the linear model) with 95 percent confidence intervals. The position of digital consumers and pirates is clearly away from the status quo, but the average position of occasional consumers is also significantly above the midpoint. 
These same results hold in the second specification, where we control for the usual sociodemographic factors. Of these factors, the effect of education, income and household size are significant (see Figure 4), while place of residence is not. Significantly, more educated respondents are more ready to change than respondents with lower educational levels, but higher levels of income are associated with lower distance to the status quo, although the effect is small.

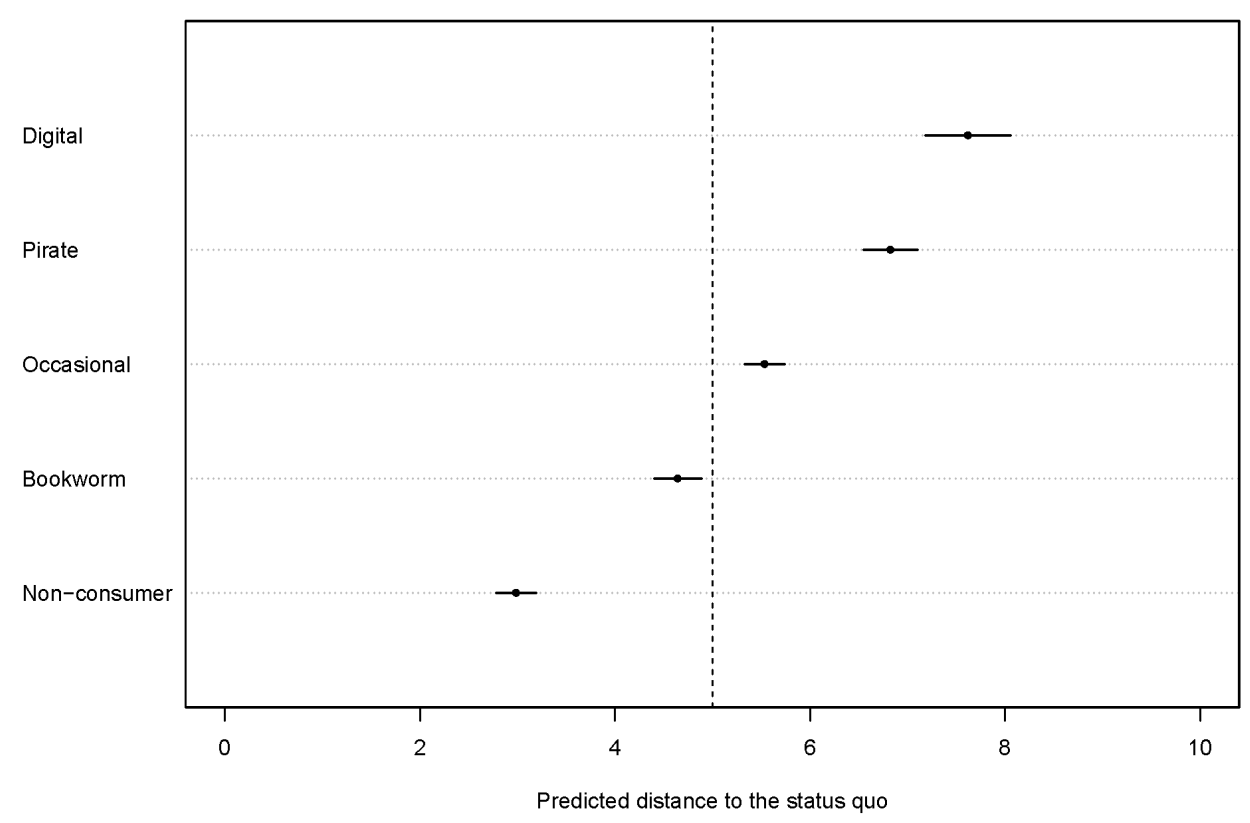

Figure 3: Predicted distance towards status quo by the different types of consumer, from the OLS model. Error bars correspond to $95 \%$ confidence intervals, and the vertical dotted line marks the midpoint in distance.

Finally, the effect of the type of consumer on the readiness to change holds also when we control for preference intensity, as shown in Figure 5. This increases the model fit substantially. Although the inclusion of preference intensity in the model mildens the effect of the type of consumer (coefficients are smaller), the same logic prevails. However, the inclusion of controls for the intensity of preferences dissipates any effect of sociodemographic factors, while preferences do make a difference: preferences on payment to artists and types of content present the strongest effects on readiness to change, while catalogue completeness has only a very mild effect. 


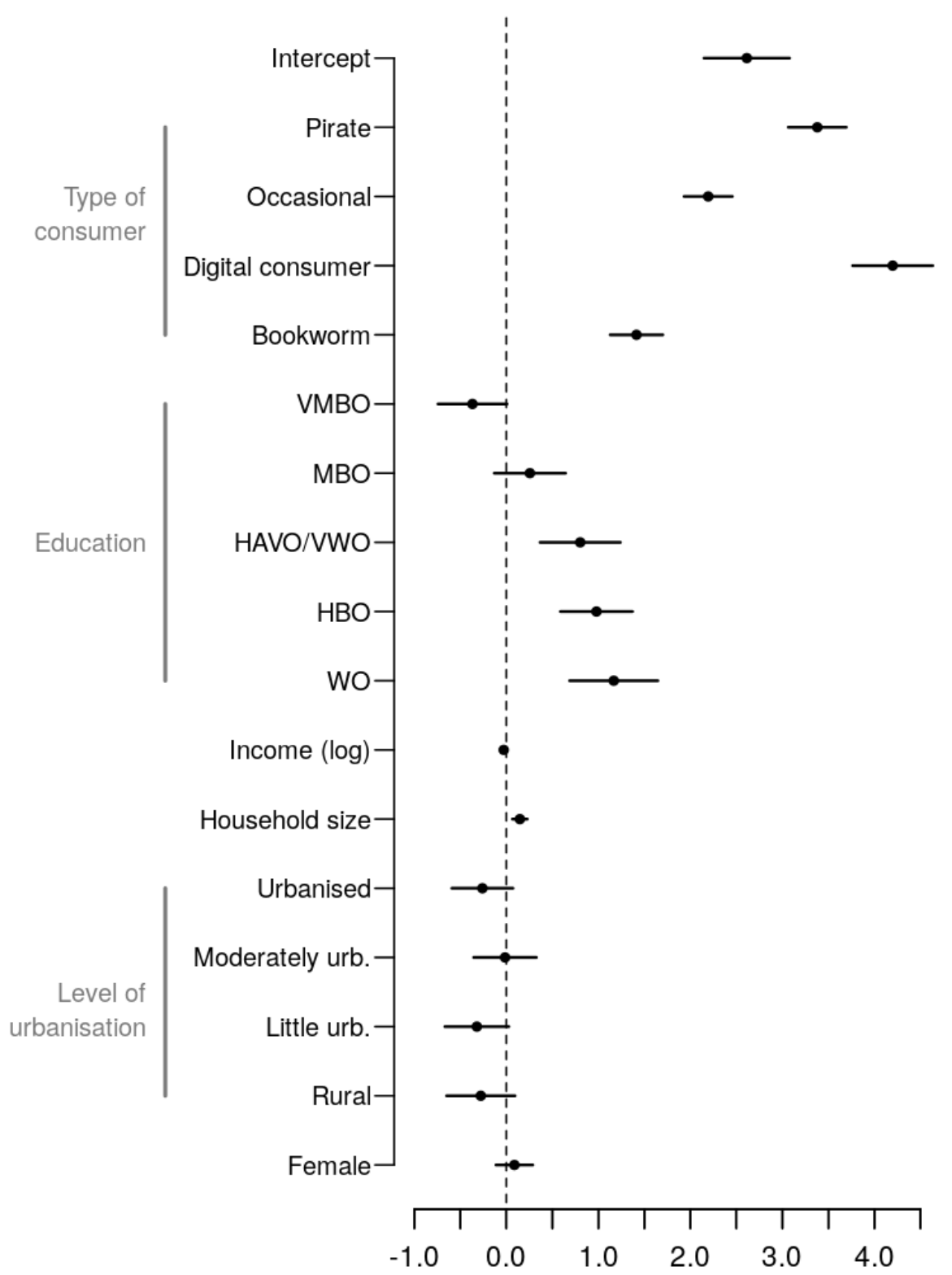

Figure 4: Coefficients of the regression model of distance towards the status quo on the type of consumer, with controls for sociodemographic factors. Values are linear regression coefficients in an OLS model, and error bars represent $95 \%$ confidence intervals.

In sum, results support the hypothesis that different types of consumers hold significantly different levels of readiness to change the status quo in copyright enforcement, and that their openness to change is robust to controls on a varied range of sociodemographic factors and preference intensity variables. However, the data do not support the naive assumption about the low incentives of digital consumers and pirates to support a change in the status quo, based on the existence of digital platforms and low levels of copyright enforcement. On the one hand, the high level of support for change among digital consumers casts doubt on the assumption that digital platforms sufficiently meet their expectations in a way that minimises their incentives to support a CCS. On the other hand, the significantly high level of support that pirates show for the implementation of a CCS is at odds with their widespread depiction as free-riders who take advantage of the low-intensity levels of copyright enforcement in the Netherlands. 


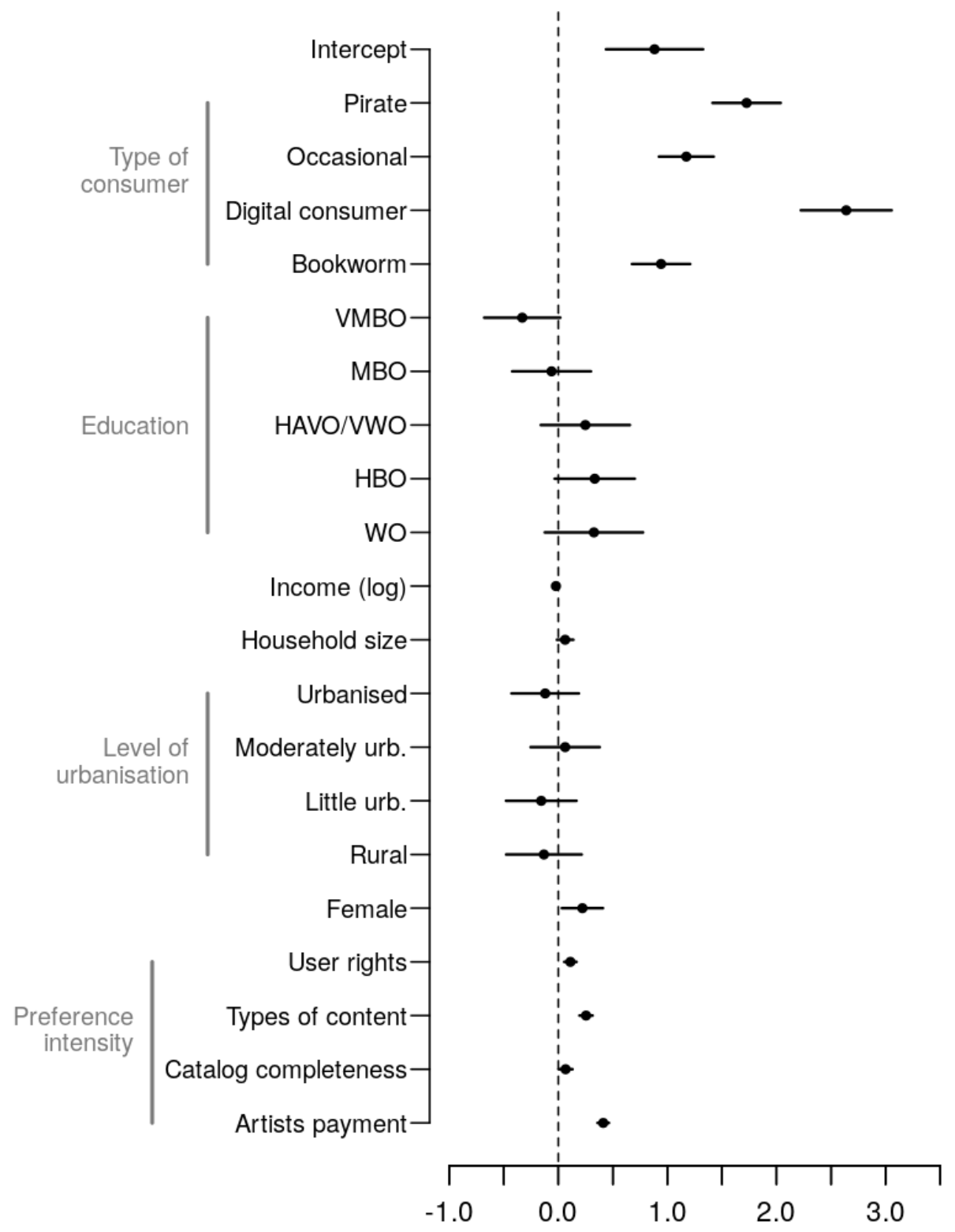

Figure 5: Coefficients of the regression model of distance towards the status quo on the type of consumer, including all controls. Values are linear regression coefficients in a OLS model, and error bars represent $95 \%$ confidence intervals.

A further robustness test to the support for change can be carried out by taking into account the price of the CCS options voted by each type of consumer. If the naive hypothesis were true, pirates would prefer CCS alternatives that maximise user rights and cultural content at the minimum price. But when we look at the average price of the CCS preferred within each cluster, we observe that digital consumers - who already pay for their cultural consumption - tend to choose alternatives at higher prices (€11.5), followed by pirates at only slightly lower average price (€9.9).A one-way ANOVA of type of consumer on average price of chosen alternative compensation system shows that average price is significantly different between types of consumers $(F(4,4863)=147.4, p<0.001)$. Results also indicate that average prices project the same order as the support for change: those more ready to change are willing to pay more. 


\section{DISCUSSION AND CONCLUDING REMARKS}

Our research offers insights into how the emergence of legal digital consumption channels structured the media consumption landscape in the Netherlands. We also discuss some of the dynamics that drive future change.

We find that nearly half (48.72\%) of our representative sample does not use digital access channels to consume music, audiovisual content or books. There are two major holdout groups: older, less educated people consume very little culture by the means we measured; older, more educated ones prefer to buy physical books only.

The younger generations show promiscuous content acquisition strategies. We distinguish three separate groups among them: digital consumers, pirates, and occasional consumers. Both pirates and digital consumers are cultural omnivores: they consume relatively high quantities of content through various free and paying channels. The main difference between is that digital consumers do not pirate, while pirates use illegal access channels alongside legal ones. Pirates tend to be much younger than digital consumers, but since income wasn't significant in any of our models, we suspect the age effect not to be an indicator of the lack of disposable income. Digital consumers and pirates make up for $6.36 \%$, and $16.02 \%$ of our sample, respectively, thus they are relatively few. Yet, they are responsible for a relatively large share of the overall cultural consumption.

The third group - occasional consumers - is the largest of our five initial clusters, with $28.88 \%$ of the sample. This group is mostly characterised by infrequent and low intensity digital consumption in general. Their use of digital channels is still mainly focused on free sampling, which is complemented by the purchase of physical copies.

Though a substantial share of our sample uses piratical access channels, there are only a few who use them exclusively (around $1 \%$ for music and films, $0.6 \%$ for books). Thus, it is very hard - if not impossible - to separate pirates from digital consumers. The use of piratical channels is only one aspect of the digital consumption landscape. Pirates are only a special subset of digital consumers, who happen to complement their legal consumption with illegal practices. In that context, the piracy-based argument in favour of a CCS seems not to be the most important.

Our study shows that despite the widespread adoption of legal free and paying online services by consumers, a CCS is preferred to the status quo both by occasional and frequent buyers of cultural goods. The more someone uses the current legal alternatives, the more they are inclined to support the CCS idea, which means that pirates and digital consumers are the most eager to change. We interpret this support as discontent with the status quo, namely with currently available legal alternatives.

Our models offer an insight into the possible sources of that discontent. The main source is revealed when our model includes the preference intensities for two CCS components: user rights and types of content. Since all alternatives for both components included a baseline, we are safe to assume that a low preference intensity means the acceptance of the common denominator, namely downloading only and access to music only. In return, we associate a strong preference intensity with a preference for more than just the baseline. ${ }_{13}$ Since both these variables yield relatively large coefficients and are statistically significant, it is safe to say that respondents who reject the status quo want access to content beyond music, and see the right to 
download as insufficient. It is worth noting that piratical access channels (such as The Pirate Bay) offer exactly these: the freedom to share and access to a wide variety of content beyond music.

Finally, we can rule out the effect of a relatively low CCS price, i.e., that digital consumers and pirates prefer a CCS alternative because they see it as a chance to save on cultural spending. Those who are the most willing to change are also the most willing to pay for an alternative system. Pirates, who actively use the free and unconstrained piratical access channels, are willing to spend nearly as much as digital consumers for a CCS alternative ( $€ 9.87$ and $€ 11.5$ respectively). That being said, the preferred price is comparable to the cost of individual streaming subscriptions, and offers significant savings if the CCS covers both music and audiovisual content.

A CCS is less attractive for occasional consumers, to whom a flat rate would possibly raise the annual cultural spending beyond their current levels, and convert the internet from a free (i.e., ad-supported) access channel into a paying one. Nevertheless, even occasional consumers are more open to change than not. For them a CCS offers the chance to expand their explorative consumption (Bodó and Lakatos,2012) beyond music and into the audiovisual and book domains. Occasional buyers are not limited to low income/low education people. Therefore, a CCS offers them a risk-free opportunity to explore and experiment with unknown cultural works, just as the free music services of yesterday enabled them to sample music without risk. Occasional consumers are apparently ready to embrace this opportunity, even if reluctantly.

As we show elsewhere, a CCS-based alternative would also benefit rights holders, since an allyou-can-eat flat-rate access model on a societal level would generate substantial extra revenues for the music industry, even if user participation were not mandatory (Handke, Bodó, and Vallbé, 2016). In certain scenarios, a CCS alternative could increase the welfare of rights holders and consumers simultaneously, while weakening the exclusive position of current digital intermediaries.

All of these arguments seem to support the consideration of CCS as a reform option. At the very least, this research points evidence-based copyright reform away from its current path in the EU ${ }_{14} \mathrm{of}$ stronger enforcement measures, additional (and broader) exclusive rights, and increased liability and duties of care for online platforms. CCS offers a way forward to curtail piracy and maximise rights revenues, while respecting fundamental rights and promoting technological development. To a point, these goals can be approximated through better private ordering, namely improvements in pricing, quality and availability of legal offers. Still, the complex fragmentation of copyright across territories, rights holders and types of use create often insurmountable difficulties in this respect. CCS-like models provide policymakers with a blueprint for legal reform alternatives based on statutory licensing (coupled with compensated exceptions) and collective rights management. These alternatives, we argue, are more consistent with user preferences in digital content distribution. 


\section{REFERENCES}

Angelopoulos, C. (2016). European Intermediary Liability in Copyright. A Tort-Based Analysis. Alphen aan den Rijn: Kluwer Law International.

Bahanovich, D., \& Collopy, D. (2009). Music experience and behaviour in young people [Technical report]. London; Hertfordshire: UK Music; University of Hertfordshire.

Bar-Ziv, S., \& Elkin-Koren, N. (2017). Behind the Scenes of Online Copyright Enforcement: Empirical Evidence on Notice \& Takedown . Connecticut Law Review, 5O(2). Available at SSRN: https://ssrn.com/abstract $=3214214$

Bodó, B., \& Lakatos, Z. (2012). Piracy Cultures | P2P and Cinematographic Movie Distribution in Hungary. International Journal of Communication, 6, 413-445. Retrieved from https://ijoc.org/index.php/ijoc/article/view/1261

Bomsel, O., \& Ranaivoson, H. (2009). Decreasing copyright enforcement costs: the scope of a graduated response. Review of Economic Research on Copyright Issues, 6(2), 13-29.

Bounies, D., Bourreau, M., \& Waelbroeck, P. (2012). Pirates or Explorers? Analysis of Music Consumption in French Graduate Schools. Brussels Economic Review, 5o(2), 167-192.

Bourdieu, P. (1984). Distinction: A Social Critique of the Judgement of Taste. London: Routledge.

Braxton, J. A. (2013). Lost in translation: The obstacles of streaming digital media and the future of transnational licensing. Hastings Communications and Entertainment Law Journal, 36(1), 193-216. Retrieved from

https://repository.uchastings.edu/hastings_comm_ent_law_journal/vol36/iss1/7

British Music Rights (2008). Music Experience and Behaviour in Young People [Technical report]. London; Hertfordshire: British Music Rights; University of Hertfordshire.

Cameron, A. C., \& Trivedi, P. K. (1998). Regression Analysis of Count Data. Cambridge: Cambridge University Press.

Cooper, M., \& Griffin, J. (2012). The role of antitrust in promoting competition and protecting consumers as the digital revolution matures: the case against the Universal-EMI merger and e-book price fixing.

Eckersley, P. (2004). Virtual Markets for Virtual Goods: The Mirror Image of Digital Copyright? [Working Paper No. 386]. Berkeley, CA: bepress. Available at https://law.bepress.com/expresso/eps/386/

Elkin-Koren, N. (2014). After twenty years: Copyright liability of online intermediaries. In S. Frankel, \& D. Gervais, (Eds.), The evolution and equilibrium of copyright in the digital age. Cambridge: Cambridge University Press.

Entertainment Media Research. (2011). 2011 Digital Entertainment Survey [Technical report]. London: Wiggin.

Fisher III, W. W. (2004). Promises to Keep, Technology, Law, and the Future of Entertainment. Stanford: Stanford University Press. 
Gelman, A., \& Hill, J. (2007). Data Analysis Using Regression and Multilevel/Hierarchical Models. New York: Cambridge University Press.

Ginsburg, J. C. (2015). Fair Use for Free, or Permitted-but-Paid? Berkeley Technology Law Journal, 29(3), 1383-1446. Retrieved from https://www.jstor.org/stable/26377572

Grassmuck, V. (2009). The World is Going Flat(-Rate). Retrieved from Intellectual Property Watch website https://www.ip-watch.org/2009/05/11/the-world-is-going-flat-rate/

Grassmuck, V., \& Stalder, F. (2003). Models for Alternative Compensation for Entertainment Content: A Critical Review. Draft v1.O. Available at https://www.vgrass.de/wpcontent/uploads/2011/o6/o3-12_vg-felix_models-berkmann-fin.pdf

Handke, C., Bodo, B., \& Vallbé, J. J. (2016). Going means trouble and staying makes it double: the value of licensing recorded music online. Journal of Cultural Economics, 4O(3), 227-259. doi:10.1007/s10824-015-9251-8

Jacques, S., Garstka, K., Hviid, M., \& Street, J. (2018). An Empirical Study of the Use of Automated Anti-Piracy Systems and Their Consequences for Cultural Diversity SCRIPTed, 15(2). doi:10.2966/scrip.150218.277

Kampmann, M. W. (2010). Online Piracy and Consumer Affect: To pay or not to pay (Master Thesis). University of Twente, Enschede, NL. Retrieved from

https://essay.utwente.nl/60470/1/MA_thesis_M_Kampmann.pdf

Kantar Media. (2012). OCI Tracker Benchmark Study Q3 2012 [Report]. London: Ofcom; Kantar Media. Available at

https://www.ofcom.org.uk/_data/assets/pdf_file/oo25/62683/kantar-media.pdf

Kunz, M. P. (2016). The influence of special interest groups on copyright law and policy-A comparison of the legislative process in the United States and Switzerland. Washington Journal of Law, Technology \& Arts, 12(1). Available at

http://digital.law.washington.edu/dspace-law/handle/1773.1/1648

Macdonald, M. (2014). Comcast v. Netflix: Why the FCC should redefine multi-channel video programming distributors to include over-the-top video providers. Colorado Technology Law Journal, 12(2), 479-497. Available at https://ctlj.colorado.edu/wpcontent/uploads/2014/11/MacDonald-website-final.pdf

Manning, C. D., Raghavan, P., \& Schütze, H. (2008). Introduction to Information Retrieval. Cambridge: Cambridge University Press.

Netanel, N. (2003). Impose a Non Commercial Use Levy to Allow Free P2P File Sharing. Harvard Journal of Law and Technology, 17(1).

Poort, J., \& Leenheer, J. (2012). File sharing 2@O2. Downloading from illegal sources in the Netherlands [Study]. Amsterdam; Tilburg: Institute for Information Law; CentERdata.

Poort, J., \& Weda, J. (2015). Elvis is returning to the building: Understanding a decline in unauthorised file sharing. Journal of Media Economics, 28(2), 63-83.

Poort, J., Quintais, J. P., van der Ende, M. A., Yagafarova, A., \& Hageraats, M. (2018). Global Online Piracy Study [Research Paper No. 2018-21] doi:10.2139/ssrn.3224323 
Quintais, J. P. (2017). Copyright in the Age of Online Access: Alternative Compensation Systems in EU Law. Alphen aan den Rijn: Kluwer Law International.

Reda, J. (2017).When filters fail: These cases show we can't trust algorithms to clean up the internet [Blog post]. Retrieved from Julia Reda's Blog https://juliareda.eu/2017/o9/whenfilters-fail/

Renkema, L., \& Karaganis, J. (Eds.) (2012). Copy Culture in the US and Germany. New York: The American Assembly. Available at https://americanassembly.org/publications/copyculture-us-and-germany-march-2013

SPEDIDAM. (2005). La licence globale optionnelle - Faire du peer-to-peer un instrument d'équilibre et de diversité. Paris: Spedidam.

Streitfeld, D. (2014, August 7). Plot thickens as 900 writers battle Amazon. The New York Times. Retrieved from https://www.nytimes.com/2014/o8/o8/business/media/plot-thickensas-900-writers-battle-amazon.html

Swedish Performing Rights Society (2009). Pirates, file-sharers and music users [Technical Report] Stockholm: Swedish Performing Rights Society.

Urban, J. M., \& Quilter, L. (2005). Efficient process or chilling effects-takedown notices under Section 512 of the Digital Millennium Copyright Act. Santa Clara Computer \& High Tech. Law Journal, 22, 621-693. Available at https://scholarship.law.berkeley.edu/facpubs/501/

Urban, J. M., Karaganis, J., \& Schofield, B. (2018). Takedown in Two Worlds: An Empirical Analysis. Journal, Copyright Society of the U.S.A., 64, 483-520.

Ward, J. H. (1963). Hierarchical grouping to optimize an objective function. Journal of the American Statistical Association, 58(301), 236-244. doi:10.1080/01621459.1963.10500845

Warner Music Group. (2010). Consumer Insights Discussion for FCC [Technical report]. New York: Warner Music Group

Watson, S., Zizzo, D., \& Fleming, P. (2014). Determinants and welfare implications of unlawful file sharing: a scoping review [Working Paper 2014/o5]. Glasgow: CREATe.

Zeileis, A. (2006). Object-oriented computation of sandwich estimators. Journal of Statistical Software, 16(9), 1-16. doi:10.18637/jss.v016.iog

\section{APPENDIX: MULTINOMIAL REGRESSION MODEL OF TYPE OF CONSUMER}

Table 3: Results of the multinomial regression model of type of consumer. Coefficients are in log-odds (standard errors within parentheses).

$$
\text { Model A }
$$

\begin{tabular}{|c|c|c|c|c|c|c|}
\hline $\begin{array}{l}-0.111^{* * *} \\
(0.008)\end{array}$ & $\begin{array}{l}-0.015^{* *} \\
(0.007)\end{array}$ & $\begin{array}{l}-0.075^{* * *} \\
(0.010)\end{array}$ & $\begin{array}{l}0.063^{* * *} \\
(0.007)\end{array}$ & $\begin{array}{l}-0.120 * * * \\
(0.010)\end{array}$ & $\begin{array}{l}-0.019^{* *} \\
(0.007)\end{array}$ & $\begin{array}{l}-0.080^{* * *}-0.068^{* * *} \\
(0.013) \quad(0.007)\end{array}$ \\
\hline
\end{tabular}


Model A

Model B

Pirate Occasional Digital Bookworm Pirate Occasional Digital Bookworm

$\begin{array}{lllllllll}\text { Age squared } & 0.0002^{*} & -0.0004^{* * *} & 0.00001 & -0.001^{* * *} & 0.0004^{* * *}-0.0003^{* * *} & 0.0002 & -0.001^{* * *} \\ & (0.0001) & (0.0001) & (0.0001) & (0.0001) & (0.0001) & (0.0001) & (0.0002) & (0.0001) \\ \text { Income (In) } & 0.013 & -0.009 & 0.018 & 0.0002 & 0.008 & -0.013 & 0.010 & -0.001 \\ & (0.015) & (0.012) & (0.018) & (0.014) & (0.015) & (0.013) & (0.019) & (0.014)\end{array}$

Education

[Ref.

Primary $]^{a}$

vmbo

$-0.093^{* * *} 0.010 \quad-0.617^{* * *} 0.472^{* * *}$

$-0.041^{* * *} 0.028$

$-0.537^{* * *} 0.466^{* * *}$

$\begin{array}{llll}(0.009) & (0.042) \quad(0.002) & (0.027)\end{array}$

(0.009) (0.042)

$0.301^{* * *} \quad 0.343^{* * *}$

$0.042^{* * *} 0.997^{* * *}$

$0.222^{* * *} \quad 0.245^{* * *}$

(0.002) (0.027)

mbo

$\begin{array}{lllll}(0.013) & (0.044) & (0.003) & (0.021)\end{array}$

(0.013) (0.044)

$-0.085^{* * *} 0.935^{* * *}$

havo/vwo

$0.824^{* * *} \quad 0.709^{* * *}$

$0.521^{* * *} 1.543^{* * *}$

$0.614^{* * *} \quad 0.547^{* * * *}$

(0.003) (0.022)

$\begin{array}{lllllll}(0.002) & \text { (0.003) (0.004) (0.002) }\end{array}$

(0.002) (0.003)

$0.731^{* * *} \quad 0.799^{* * *}$

$0.230^{* * *} 1.459^{* * *}$

hbo

$0.964^{* * *} 0.984^{* * *}$

$0.708^{* * *} 1.807^{* * * *}$

(0.010) (0.041)

$1.513^{* * *} \quad 1.274^{* * *} \quad 1.343^{* *} \quad 2.216^{* * *}$

$1.101^{* * *} \quad 0.961^{* * *}$

(0.005) (0.002)

wo

(0.002) (0.005)

(0.001) (0.003)

(0.002) (0.005)

$1.695^{* * * *}$

(0.003) (0.029)

Household

$-0.128^{* * *}-0.071^{*}$

$\begin{array}{ll}0.064 & -0.054\end{array}$

$-0.137^{* * *}-0.083^{* *}$

$0.869^{* * * 2.062^{* * *}}$

size

(0.043) (0.036)

(0.053) (0.041)

(0.045) (0.037)

Residence

[Ref. Highly

urb.]

Urbanised

$0.298^{* * *} 0.172^{* * *}$

$0.063^{* * *} 0.151^{* * *}$

$0.327^{* * *} \quad 0.178^{* * *}$

$0.077^{* * *} \quad 0.152^{* * *}$

(0.015) (0.046)

(0.003) (0.023)

(0.014) (0.043)

(0.003) (0.023)

Moderately

urb.

$0.069^{* * *} 0.059$

$-0.312^{* * *} 0.076^{* * *}$

$0.055^{* * *} 0.039$

$-0.342^{* * *} 0.066^{* * *}$

(0.015) (0.047)

(0.003) (0.023)

(0.014) (0.043)

(0.003) (0.023)

Little

$0.117^{* * *} \quad 0.045$

$-0.339^{* * *} 0.125^{* * *}$

$0.175^{* * *} \quad 0.072^{*}$

$-0.284^{* * *} 0.125^{* * *}$

(0.012) (0.047)

(0.003) (0.029)

(0.011) (0.041)

(0.003) (0.025)

Not

$-0.165^{* * *} 0.008$

$-0.438^{* * *}-0.001$

$-0.122^{* * *} 0.026^{* * *}$

$-0.405^{* * *} 0.005^{*}$

(0.013) (0.052)

(0.003) (0.028)

(0.002) (0.007)

(0.001) (0.003)

Sex

$$
-0.874^{* * *}-0.080
$$

$-0.622^{* * *} 0.414^{* * *}$

$-0.819^{* * *}-0.032$

$-0.542^{* * *} 0.465^{* * *}$

(0.019) (0.053)

(0.003) (0.025)

(0.018) (0.054)

(0.005) (0.027)

Preference

intensity

User rights

Types of

content

Catalog

completeness

$\begin{array}{llll}\begin{array}{ll}0.061^{*} \\ (0.034)\end{array} & \begin{array}{l}-0.009 \\ (0.028)\end{array} & \begin{array}{l}0.077^{*} \\ (0.043)\end{array} & \begin{array}{l}-0.028 \\ (0.030)\end{array} \\ 0.259^{* * *} & 0.190^{* * *} & 0.272^{* * *} & 0.063^{* *} \\ (0.036) & (0.029) & (0.046) & (0.031) \\ 0.122^{* * *} & 0.083^{* * *} & 0.090^{*} & 0.049 \\ (0.038) & (0.032) & (0.047) & (0.034) \\ 0.014 & 0.029 & 0.048 & 0.078^{* * *} \\ (0.031) & (0.026) & (0.039) & (0.028) \\ 2.962^{* * *} & 0.903^{* * *} & 0.737^{* * *} & -3.736^{* * *} \\ (0.001) & (0.002) & (0.001) & (0.001)\end{array}$

Artists

payment

Constant

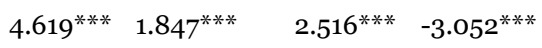

(0.001)

Akaike Inf.

Crit.

$12,300.5 \quad 12,300.5$

$12,300.5 \quad 12,300.5$

$\begin{array}{llll}11,720.34 & 11,720.34 & 11,720.34 & 11,720.34\end{array}$

$p<0.1 ;{ }^{\square} p<0.05 ;{ }^{\square} p<0.01$

${ }^{a}$ Dutch educational levels refer to: VMBO (pre-vocational), MBO (vocational), HAVO/VWO (secondary), WO (higher education)

FOOTNOTES

1. The main international treaties in this respect are the Berne Convention for the Protection of Literary and Artistic Works, the 1994 Agreement on Trade-Related Aspects of Intellectual 
Property Law (TRIPS) and, in relation to use over digital networks, the 1996 WIPO Copyright Treaty, and the WIPO Performances and Phonograms Treaty.

2. See: Directive 2001/29/EC of 22 May 2001 on the harmonisation of certain aspects of copyright and related rights in the information society, OJ L 167/10, 22.06.2001 [InfoSoc Directive]; Directive 2004/48/EC of the European Parliament and of the Council of 29 April 2004 on the enforcement of intellectual property rights, OJ L 157, 30.04.2004 [Enforcement Directive]; Directive 2000/31/EC of the European Parliament and of the Council of 8 June 2000 on certain legal aspects of information society services, in particular electronic commerce, in the Internal Market, OJ L 178, 17.7.2000, p. 1-16 [E-Commerce Directive].

3. The final version of the Directive was approved by the EU Parliament on 26 March 2019 and the Council on 15 April 2019. At the time of writing, the final text had not been published but the approved version can be accessed at:

http://www.europarl.europa.eu/doceo/document/A-8-2018-0245-AM-271-271_EN.pdf. NB: The definition of "online content-sharing provider is found in Article 2(6). In addition, Article 17 creates a specific regime for these providers outside the hosting safe-harbour in Article 14 of the E-Commerce Directive.

4. There are very few holdout artists whose work is not available digitally. The Beatles' catalog only became available at the end of 2015, and King Crimson's only very recently (2017). There are also artists who only license one platform rather than all, or temporarily withhold their latest works from certain platforms.

5. Considerable time has passed since the date of the survey on which the empirical analysis of this paper is based (2012). Yet, half a decade later the fundamental conditions of digital cultural access haven't changed in the Netherlands. Consistent with other studies on legal and illegal access in the Netherlands (Poort and Leenheer, 2012), we measured that around $17 \%$ of the population accessed music from illegal sources in 2012 in the preceding year. A recent study (Poort et al., 2018) reports that $19 \%$ of the total population still accessed music through such illegal channels. While free and paid legal access alternatives became more popular during that period, this apparently did not translate into a substantial drop in illegal access. Therefore, our fundamental research question about the consumer desirability of state mandated Alternative Compensation Systems (ACS) that would "legalise piracy" is still valid.

\section{6. http://www.lissdata.nl/lissdata}

7. Time is measured through six intervals, from "less than a week ago" to "more than a year ago", while the amount of consumption is measured in five categorical intervals from one unit (album, film, book) to more than 20, except for paid subscriptions, which are measured as the monthly household expenditure.

8. Regarding the specific clustering method, we use Hierarchical Agglomerative Clustering (HAC) (Manning et al., 2008), which compared to flat methods such as k-means clustering, does not need the prior specification of a number of clusters into which the data must be partitioned. In order to minimise the within-cluster variance we use Ward's minimum variance method (Ward, 1963). In the end, each respondent is classified exclusively into one cluster.

9. Although our raw measure of distance is a continuous variable, it is actually bounded count data - with strict integer value range $[0,12]$. In addition, this variable is zero-inflated. Modeling variation of this kind of data through linear models may cause estimation problems, given that 
OLS assumes that values are normally distributed and that the response variable can take any real value (Cameron and Trivedi, 1998). Count data can be better modeled through log-linear regression models that assume more realistic distributions in the response data, such as Poisson (Gelman and Hill, 2007). To that effect, we run robustness checks fitting a Poisson regression model to explain variation in distance to the status quo as a function of the type of consumer, with robust, heteroskedasticity-consistent standard errors for the parameter estimates (Zeileis, 2006).

10. The expression "cultural omnivores" intends to convey a wide variety of channels of cultural consumption rather than an intense or voluminous cultural consumption pattern.

11. For the sake of visualisation, age has been recoded into a categorical variable with 10-year interval categories.

12. Due to space limits, complete tabular results of both OLS and Poisson regression may be available upon request.

13. Unless we assume theoretically that respondents have a strong preference for the option that offers them less.

14. See Section 2 supra, in particular Article 17 of the Copyright in the Digital Single Market Directive . 